\title{
ANALISIS PERAMALAN BEBAN TRANSFORMATOR JARINGAN DISTRIBUSI PADA PT. PLN ULP AMBULU PENYULANG JATIMULYO MENGGUNAKAN METODE REGRESI LINIER
}

\section{Analysis of Load Forecasting Distribution Transformer in PT. PLN ULP Ambulu Jatimulyo Feeder using Linier Regression Method}

\author{
Syayyidatun Nur Dina ${ }^{[1]}$, Samsul Bachri M. ${ }^{[2]}$, Satryo Budi Utomo ${ }^{[2]}$ \\ ${ }^{[1]}$ Jurusan Teknik Elektro, Fakultas Teknik, Universitas Jember \\ ${ }^{[2]}$ Staf Pengajar Jurusan Teknik Elektro, Fakultas Teknik, Universitas Jember \\ JIn. Kalimatan no 37, Krajan Timur, Sumbersari, Jember, INDONESIA \\ Email: syayyidatundina@gmail.com: bachri170364@yahoo.com : satryo@unej.ac.id
}

\begin{abstract}
ABSTRAK
Kehandalan dan kestabilan sistem distribusi pada Penyulang Jatimulyo sangat penting untuk menunjang kelancaran penyaluran sistem tenaga listrik karena merupakan salah satu daerah wisata. Salah satu upaya memperhatikan kondisi tersebut dengan menjaga sistem perawatan transformator, agar kebutuhan energi listrik dapat terpenuhi kedepannya. Peramalan beban transformator distribusi sangat diperlukan guna membantu mengambil kebijaksanaan penambahan beban baik jangka panjang, pendek maupun menengah. Adapun data yang digunakan adalah data beban puncak penyulang Jatimulyo dengan kapasitas 100 kVA dan 160 kVA dengan total sebanyak 44 trafo, jumlah penduduk dan PDRB Kabupaten Jember dari tahun 2016-2020. Metode yang digunakan pada penelitian ini adalah metode Regresi linier berganda dimana, Transformator yang menjadi sample perhitungan adalah GE007 160 kVA dan trafo GE089 100 kVA. Beban Puncak pada Transformator Distribusi dapat menjadi salah satu bahan pertimbangan yang digunakan untuk mengupgrade atau menggati dengan transformator yang baru. apabila pembebanan diatas $80 \%$, maka transformator akan mengalami pembebanan berlebih /overload sehingga kinerja transformator tidak optimal.
\end{abstract}

Kata kunci : Peramalan Beban, Transformator, Distribusi, Prosentase Pembebanan, Regresi Linier.

\section{ABSTRACT}

The reliability and stability distribution system at the Jatimulyo Feeder is very important, in order to support the smooth distribution of the electric power system because it is one of the tourist areas. One of the efforts to pay attention to this condition is by maintaining the transformer maintenance system, so that electrical energy needs can be fulfill in the future. Load forecasting distribution transformer is needed to help take the policy of adding loads both in the long, short and medium term. The data used are the peak load data of Jatimulyo feeders with a capacity of $100 \mathrm{kVA}$ and $160 \mathrm{kVA}$ with a total of 44 transformers, population and PDRB of Jember Regency from 2016-2020. The method used in this study with linear regression method, which the transformer that be calculation sample is the GE007 $160 \mathrm{kVA}$ and the transformer GE089 $100 \mathrm{kVA}$. The peak load on the distribution transformer can be one of the considerations used to upgrade or replace with a new transformer. if the load is above $80 \%$, the transformer will overload, so that the transformer performance is not optimal.

Keywords: Load Forecasting, Transformer, Distribution, \% of Load, Linier Regression.

\section{PENDAHULUAN}

Sumber tenaga listrik sekarang ini telah menjadi kebutuhan primer bagi kehidupan manusia dan perkembangan teknologi. Sekarang ini kebutuhan listrik telah meningkat drastis, tidak bisa dibayangkan dunia tanpa energi listrik. Sistem tenaga listrik dirancang untuk dapat mengirim tenaga listrik dengan cara efisien dan aman sampai pada pelanggan atau konsumen. Disamping itu pada operasi sistem tenaga listrik, kehandalan dan kestabilan sistem distribusi sangat penting guna menunjang kelancaran penyaluran tenaga listrik. Salah satu upaya untuk mempertahankan kehandalan dan kestabilan suatu sistem 
tenaga listrik yaitu dengan memperhatikan kondisi dari peralatan-peralatan tenaga listrik yang ada, antara lain menjaga sistem dengan perawatan transformator.

Transformator adalah peralatan pada sistem tenaga listrik yang digunakan untuk mengubah energi listrik. Perawatan transformator sangat penting dijaga kelanjutannya demi menyalurkan ke sistem distribusi. Kondisi ini tentunya harus diantisipasi sedini mungkin agar ketersediaan energi listrik dapat tersedia dalam jumlah yang cukup.

Menjamin suplai tegangan listrik dari pembangkit ke konsumen memerlukan suatu transformator yang mampu menanggung permintaan beban konsumen, hal ini PT. (PLN) sebagai pemasok tegangan listrik perlu mengevalusi transfomator yang ada dalam melayani kebutuhan beban listrik. Maka dibutuhkanlah prakiraan atau peramalan beban transformator pada sistem distribusi. Perkiraan beban adalah tentang memperkirakan konsumsi di masa mendatang berdasarkan berbagai data dan informasi yang tersedia dan sesuai dengan perilaku konsumen. Peramalan terhadap kebutuhan transformator sangat diperlukan untuk membantu mengambil kebijaksanaan penambahan energi listrik dan transformator baik jangka panjang, pendek maupun menengah, sehingga kapasitas energi dan transformator pada masa mendatang dapat diprediksi dan dapat meminimalisir masalah-masalah yang ada.

\section{KAJIAN PUSTAKA}

\section{A. Survey dan Pengambilan Data}

Melakukan pengambilan data dari PT. PLN Unit Layanan Pelanggan (ULP) Ambulu, dan BPS (Badan Pusat Statistik) Kabupaten Jember. Data yang diperoleh merupakan data beban puncak transformator distribusi dengan kapasitas 100 kVA dan 160 kVA pada penyulang Jatimulyo serta Jumlah Penduduk dan PDRB Kabupaten Jember dari tahun 2016 sampai tahun 2020 yang digunakan untuk penelitian peramalan beban

\section{B. Pengolahan Data}

Data yang telah dikumpulkan dan didapatkan kemudian dilakukan pengolahan data beban puncak transformator dengan menggunakan metode Regresi Linier yang digunakan dalam peramalan beban sampai lima tahun mendatang dari tahun 2021 sampai tahun 2025. Pengolahan data terdiri dari 2 tahapan yaitu :

1. Pengolahan data berdasarkan pada Pengelompokan data Statistik

2. Pengolahan data berdasarkan pada Pengelompokan data Kelistrikan

\section{Regresi Linier}

Metode analisis data yang digunakan dalam penelitian ini yaitu menggunakan data kuantitatif. Sebelum mendapatkan hasil dan keputusan suatu penelitian maka data harus diolah dan dianalisis terlebih dahulu sehingga dapat menjadi dasar dalam pengambilan keputusan

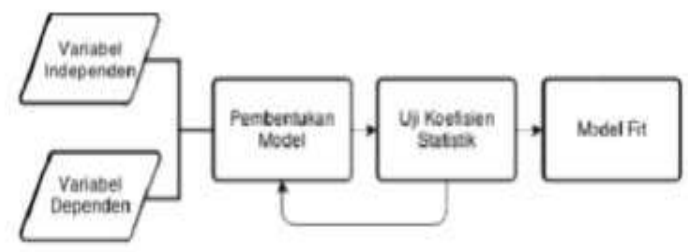

Gambar 1. Diagram Pembuatan model Regresi Linier Berganda

\section{C.1. Uji Keterandalan Model (Uji $F)$}

Uji $F$ merupakan tahapan awal mengidentifikasi model regresi yang diestimasi layak atau tidak. Layak (andal) disini maksudnya adalah model yang diestimasi layak digunakan untuk menjelaskan pengaruh variabel-variabel bebas terhadap variabel terikat. Apabila nilai prob. $F$ lebih kecil dari tingkat kesalahan/error (alpha) 0,05) maka dapat dikatakan bahwa model regresi yang diestimasi layak, sedangkan apabila nilai prob. $F$ hitung lebih besar dari tingkat kesalahan 0,05 maka dapat dikatakan bahwa model regresi yang diestimasi tidak layak.

\section{C.2. Uji Koefisien Regresi (Uji $t)$}

Uji $t$ dalam regresi linier berganda dimaksudkan untuk menguji apakah parameter (koefisien regresi dan konstanta) yang diduga untuk mengestimasi persamaan/model regresi linier berganda sudah merupakan parameter yang tepat atau belum. Apabila nilai prob. $t$ lebih kecil dari tingkat kesalahan (alpha) 0,05 maka dapat dikatakan bahwa variabel bebas (dari $t$ hitung tersebut) berpengaruh signifikan terhadap variabel terikatnya. 


\section{C.3. Analisis Korelasi $\left(\mathrm{R}^{2}\right)$}

Analisis korelasi ganda digunakan untuk menunjukan seberapa besar hubungan yang terjadi antara variabel independen secara serentak terhadap variabel dependen, dengan rumus :

$\mathrm{R}^{2}=\left\{\left(\mathrm{b}_{1} \quad \Sigma \mathrm{X}_{1} \mathrm{Y}\right)+\left(\mathrm{b}_{2} \quad \Sigma \mathrm{X}_{2} \mathrm{Y}\right)\right\} /$ $\Sigma Y^{2} \ldots \ldots \ldots \ldots \ldots \ldots . . .(2)$

Representasi dari hasil pearson product moment ( $r$ ) dapat menunjukkan tingkat korelasi antar variabel. Tingkat korelasi tersebut dapat dilihat pada Tabel 1.

Tabel 1. Tingkat korelasi antar variable

\begin{tabular}{|c|c|c|}
\hline No & Nilai $(\mathbf{r})$ & Tingka Korelasi \\
\hline 1 & 0 & Tidak ada korelasi \\
\hline 2 & $0.01-0.25$ & Korelasi sangat lemah \\
\hline 3 & $0.26-0.50$ & Korelasi cukup \\
\hline 4 & $0.51-0.75$ & Korelasi kuat \\
\hline 5 & $0.76-0.99$ & Korelasi sangat kuat \\
\hline 6 & 1 & Korelasi sempurna \\
\hline
\end{tabular}

\section{C.4. Model Persamaan Regresi}

Tujuan analisis regresi linier berganda adalah untuk mengukur intensitas hubungan antara dua variabel atau lebih dan membuat prediksi perkiraan nilai $Y$ atas $X$. Data yang digunakan adalah data beban puncak Transformator Distribusi dan data BPS Jember berupa tentang jumlah penduduk dan PDRB (Produk Domestik Regional Bruto). Beban sebagai variable tak bebas (Y) jumlah penduduk dan PDRB sebagai variabel beba $(x 1, x 2)$, a sebagai konstanta dan $b 1, b 2$ sebagai koefesien regresi diperoleh melalui persamaan regresi.

Rumus regresi linear ganda untuk peramalan beban yaitu :

$$
\begin{aligned}
& Y=a+b_{1} X_{1}+
\end{aligned}
$$

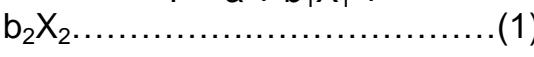

\section{Perhitungan Pembebanan}

Pembebanan Transformator didapat dari hasil peramalan dibagai dengan kapasitas transformator. Berdasarkan SPT PLN No 50 Tahun 1997, batas optimal pembebanan transformator sebesar $60-80 \%$. Sehingga diklasifikasikan pembebanan trafo sebagai berikut:

\author{
$0-60 \%=$ Beban Ringan \\ $60-80 \%=$ Beban Optimal \\ $>80 \%=$ Beban Berat \\ Untuk menghitung presentase \\ pembebanan trafo digunakan rumus \\ sebagai berikut: \\ \%pembebanan \\ $=\frac{a x}{k \text { transformator }} x: 100 \ldots \ldots \ldots . .(3)$
}

Berdasarkan persamaan diatas, $S \mathrm{x}$ merupakan pembebanan transformator sudah terpakai selama beropasi (kVA). Sedangkan Ktrasformator merupakan kapasitas transformator yang terpasang (kVA).

\section{HASIL DAN PEMBAHASAN}

Analisis data penelitian diawali dengan menganalisa dan meramal pertumbuhan penduduk dan PDRB setiap tahun, untuk 5 tahun kedepan Setelah itu dapat menganalisis beban puncak tertinggi setiap tahun untuk transformator distribusi yang telah ditetapkan dengan kapasitas 100 kVA dan 160 kVA pada penyulang Jatimulyo sebagai variabel terikatnya, dengan variabel bebasnya adalah jumlah penduduk dan PDRB wilayah tersebut, kemudian dapat membuat persamaan regresi pendekatan dengan metode regesi linier berganda menggunakan Sofware SPPS. Setelah itu didapatkan hasil meramalkan pembebanan yang terjadi pada transformator distribusi, agar dapat mengetahui batas kemampuan transformator distribusi untuk 5 tahun kedepan.

Pada Penelitian ini terdapat 44 buah Transformator distribusi pada penyulang Jatimulyo. Transformator yang di contohkan atau menjadi sample perhitungan adalah transformator dengan tipe GE007 pada desa Sabrang dengan kapasitas 160 kVA dan transformator GE089 kapasitas 100 kVA pada desa Sumberejo.

\section{A. Transformator GE007 160 kVA Desa Sabrang}

Transformator GE007 merupakan salah satu transformator dengan kapasitas 160 kVA yang ada di penyulang Jatimulyo, untuk mengetahui hasil peramalan beban transformator, terlebih dahulu harus mengetahui data beban puncak, jumlah penduduk dan PDRB pada daerah tersebut pada tahun 2016 - 2020 , kemudian dapat 
diketahui persamaan regresinya melalui software SPSS yaitu:

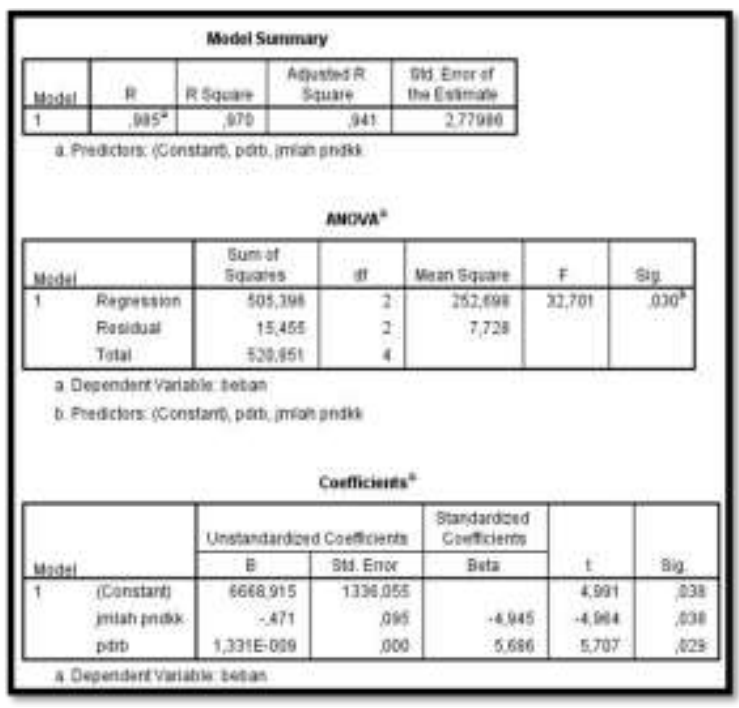

Gambar 2. Persamaan Regresi Transformator GE007 160 kVA pada SPSS

\section{A. 1 Uji $F$ dan Uji $t$}

Uji $t$ berguna untuk mengetahui pengaruh variable $X$ secara partial (sendirisendiri) terhadapat variabel Y. Sementara uji $F$ bertujuan untuk mengetahui pengaruh variable $X$ secara bersama-sama atau gabungan terhadap variabel $\mathrm{Y}$, maka, didapatkan kesimpulan sebagai berikut:

- Pengujian Hipotesis Pertama (H1)

Diketahui nilai Sig untuk pengaruh $\mathrm{X} 1$ jumlah penduduk dan $Y$ beban adalah sebesar $0,038<0,05$ dan nilai $t$ hitung $4,964<4,303$, sehingga dapat disimpulkan terdapat pengaruh $\mathrm{X} 1$ terhadap $\mathrm{Y}$ dan $\mathrm{H} 1$ diterima.

- Pengujian Hipotesis Kedua (H2)

Diketahui nilai Sig untuk pengaruh X2 PDRB dan $Y$ beban adalah sebesar 0,029 < 0,05 dan nilai $t$ hitung 5,707 > 4,303, sehingga dapat disimpulkan terdapat pengaruh $\mathrm{X} 2$ terhadap $\mathrm{Y}$ dan $\mathrm{H} 2$ diterima.

- Pengujian Hipotesis Ketiga (H3)

Berdasarkan output diatas, diketahui nilai Sig untuk pengaruh $X 1$ dan $X 2$ secara bersama-sama terhadap $Y$ beban adalah sebesar $0,030<0,05$ dan nilai $F$ hitung $32,701>9,55$, sehingga dapat disimpulkan terdapat pengaruh $\mathrm{X} 1$ dan $\mathrm{X} 2$ secara bersama-sama terhadap $\mathrm{Y}$ dan $\mathrm{H} 3$ diterima.

\section{A.2 Pengaruh $R^{2}$ pada output SPSS GE007}

Berdasarkan tabel output SPSS "Model Summary" diatas, diketahui nilai koefisien determinasi atau $R$ square $\left(R^{2}\right)$ sebesar 0,970 . Angka tersebut mengandung arti bahwa variabel jumlah penduduk (X1) dan variabel PDRB (X2) secara simultan (bersama-sama) berpengaruh terhadap variabel beban (Y) sebesar 97\%. Selanjutnya semakin kecil nilai koefisien determinasi $\left(R^{2}\right)$, maka artinya pengaruh variable bebas $(X)$ terhadap variable terikat (Y) semakin lemah. Sebaliknya, jika nilai $\left(R^{2}\right)$ semakin mendekati angka 1, maka pengaruh tersebut akan semakin kuat.

\section{A.3 Persamaan Regresi Transformator GE007}

Pada output SPSS didapatkan hasil persamaan sebesar $Y=6699,915$ $0,472(x 1)+1,331 e-009$, maka didapat hasil peramalan beban untuk 5 tahun kedepan mulai tahun 2021 - tahun 2025 seperti pada tabel berikut ini:

Tabel 2. Hasil peramalan Transformator GE007

\begin{tabular}{|c|c|c|c|c|c|}
\hline $\begin{array}{c}\text { Tahu } \\
\mathbf{n}\end{array}$ & pdkk & $\begin{array}{c}\text { PDRB } \\
\text { Juta Rp }\end{array}$ & $\begin{array}{c}\text { Beban } \\
\mathbf{( k V A )}\end{array}$ & $\begin{array}{c}\text { Pembe } \\
\text { ba-nan } \\
(\%)\end{array}$ & $\begin{array}{c}\text { Kon } \\
\text { disi }\end{array}$ \\
\hline 2016 & 15.006 & 387.790 & 116,42 & 72,76 & $\begin{array}{c}\text { Opti } \\
\text { mal }\end{array}$ \\
\hline 2017 & 15.116 & 419.170 & 108,25 & 67,65 & $\begin{array}{c}\text { Opti } \\
\text { mal }\end{array}$ \\
\hline 2018 & 15.186 & 448.824 & 112,88 & 70,55 & $\begin{array}{c}\text { Opti } \\
\text { mal }\end{array}$ \\
\hline 2019 & 15.252 & 480.675 & 121,49 & 75,93 & $\begin{array}{c}\text { Opti } \\
\text { mal }\end{array}$ \\
\hline 2020 & 15.314 & 511.192 & 137,86 & 86,16 & $\begin{array}{c}\text { Ber } \\
\text { at }\end{array}$ \\
\hline 2021 & 15.400 & 542.023 & 136,72 & 85,45 & $\begin{array}{c}\text { Ber } \\
\text { at }\end{array}$ \\
\hline 2022 & 15.476 & 572.854 & 142,34 & 88,96 & $\begin{array}{c}\text { Ber } \\
\text { at }\end{array}$ \\
\hline 2023 & 15.551 & 603.685 & 147,95 & 92,47 & $\begin{array}{c}\text { Ber } \\
\text { at }\end{array}$ \\
\hline 2024 & 15.626 & 634.516 & 153,56 & 95,98 & $\begin{array}{c}\text { Ber } \\
\text { at }\end{array}$ \\
\hline 2025 & 15.701 & 665.347 & 159,18 & 99,49 & $\begin{array}{c}\text { Ber } \\
\text { at }\end{array}$ \\
\hline
\end{tabular}

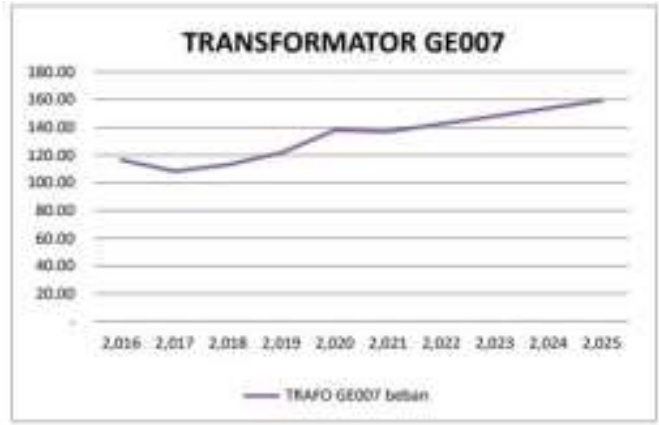

Gambar 3. Grafik pertumbuhan beban transformator GE007 untuk tahun 2016-2025 


\section{B. Transformator GE007 160 kVA Desa Sabrang}

Transformator GE089 mempunyai kapasitas sebesar 100 kVA, kemudian untuk mengetahui hasil peramalan beban transformator, terlebih dahulu harus mengetahui data beban puncak, jumlah penduduk dan PDRB dari tahun 2016 2020 pada wilayah tersebut, kemudian dapat diketahui persamaan regresinya melalui software SPSS seperti berikut ini:

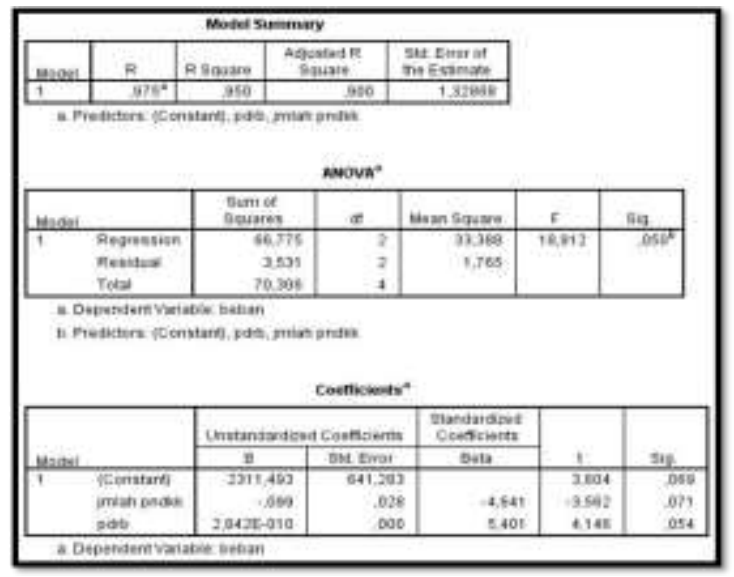

Gambar 4. Persamaan Regresi Transformator GE089 100 kVA pada SPSS

\section{B.1 Uji F dan Uji t}

Uji $t$ berguna untuk mengetahui pengaruh variable $X$ secara partial (sendirisendiri) terhadapat variabel $Y$. Sementara uji $F$ bertujuan untuk mengetahui pengaruh variable $X$ secara bersama-sama atau gabungan terhadap variabel $\mathrm{Y}$, maka, didapatkan kesimpulan sebagai berikut:

- Pengujian Hipotesis Pertama ( $\mathrm{H} 1)$

Diketahui nilai Sig untuk pengaruh $\mathrm{X} 1$ jumlah penduduk dan $\mathrm{Y}$ beban adalah sebesar $0,071>0,05$ dan nilai t hitung $3,562<4,303$, sehingga dapat disimpulkan terdapat pengaruh $\mathrm{X} 1$ terhadap $\mathrm{Y}$ dan $\mathrm{H} 1$ ditolak.

- Pengujian Hipotesis Kedua (H2)

Diketahui nilai Sig untuk pengaruh $\mathrm{X} 2$ PDRB dan $Y$ beban adalah sebesar 0,054 > 0,05 dan nilai $t$ hitung $4,146<4,303$, sehingga dapat disimpulkan terdapat pengaruh $\mathrm{X} 2$ terhadap $\mathrm{Y}$ dan $\mathrm{H} 2$ ditolak.

- Pengujian Hipotesis Ketiga (H3)

Berdasarkan output diatas, diketahui nilai Sig untuk pengaruh $X 1$ dan $X 2$ secara bersama-sama terhadap $\mathrm{Y}$ beban adalah sebesar $0,050<0,05$ dan nilai $F$ hitung $18,912>9,55$, sehingga dapat disimpulkan terdapat pengaruh $\mathrm{X} 1$ dan $\mathrm{X} 2$ secara bersama-sama terhadap $\mathrm{Y}$ dan $\mathrm{H} 3$ diterima.

\section{B.2 Pengaruh $R^{2}$ pada output SPSS GE089}

Berdasarkan tabel output SPSS "Model Summary" diatas, diketahui nilai koefisien determinasi atau $R$ square $\left(R^{2}\right)$ sebesar 0,950 . Angka tersebut mengandung arti bahwa variabel jumlah penduduk (X1) dan variabel PDRB (X2) secara simultan (bersama-sama) berpengaruh terhadap variabel beban (Y) sebesar 95\%. Sedangkan sisanya $(100 \%-95 \%=0,5 \%)$ dipengaruhi oleh variable lain diluar persamaan regresi ini atau variable yang tidak diteliti. semakin kecil nilai koefisien determinasi $\left(R^{2}\right)$, maka artinya pengaruh variable bebas $(X)$ terhadap variable terikat (Y) semakin lemah. Sebaliknya, jika nilai $\left(R^{2}\right)$ semakin mendekati angka 1, maka pengaruh tersebut akan semakin kuat.

Tabel 3. Hasil peramalan Transformator GE089 160 kVA Desa Sabrang

\begin{tabular}{|c|c|c|c|c|c|}
\hline $\begin{array}{c}\text { Tahu } \\
n\end{array}$ & pdkk & $\begin{array}{c}\text { PDRB } \\
\text { Juta Rp }\end{array}$ & $\begin{array}{c}\text { Beba } \\
n \\
(\mathrm{kVA})\end{array}$ & $\begin{array}{c}\text { Pembe } \\
\text { ba-nan } \\
(\%)\end{array}$ & $\begin{array}{c}\text { Kond } \\
\text { isi }\end{array}$ \\
\hline 2016 & 24.523 & $\begin{array}{c}633.73 \\
2\end{array}$ & 56,37 & 56,37 & $\begin{array}{c}\text { Ring } \\
\text { an }\end{array}$ \\
\hline 2017 & 24.703 & $\begin{array}{c}685.02 \\
1\end{array}$ & 53,80 & 53,80 & $\begin{array}{c}\text { Ring } \\
\text { an }\end{array}$ \\
\hline 2018 & 24.817 & $\begin{array}{c}733.47 \\
0\end{array}$ & 55,68 & 55,68 & $\begin{array}{c}\text { Ring } \\
\text { an }\end{array}$ \\
\hline 2019 & 24.925 & $\begin{array}{c}785.52 \\
6\end{array}$ & 58,21 & 58,21 & $\begin{array}{c}\text { Ring } \\
\text { an }\end{array}$ \\
\hline 2020 & 25.027 & $\begin{array}{c}835.39 \\
5\end{array}$ & 64,70 & 64,70 & $\begin{array}{c}\text { Opti } \\
\text { mal }\end{array}$ \\
\hline 2021 & 25.168 & $\begin{array}{c}885.77 \\
8\end{array}$ & 71,62 & 71,62 & $\begin{array}{c}\text { Opti } \\
\text { mal }\end{array}$ \\
\hline 2022 & 25.291 & $\begin{array}{c}936.16 \\
1\end{array}$ & 73,77 & 73,77 & $\begin{array}{c}\text { Opti } \\
\text { mal }\end{array}$ \\
\hline 2023 & 25.414 & $\begin{array}{c}986.54 \\
4\end{array}$ & 75,91 & 75,91 & $\begin{array}{c}\text { Opti } \\
\text { mal }\end{array}$ \\
\hline 2024 & 25.537 & $\begin{array}{c}103692 \\
7\end{array}$ & 78,05 & 78,05 & $\begin{array}{c}\text { Opti } \\
\text { mal }\end{array}$ \\
\hline 2025 & 25.660 & $\begin{array}{c}108731 \\
0\end{array}$ & 80,20 & 80,20 & $\begin{array}{c}\text { Berat } \\
\end{array}$ \\
\hline
\end{tabular}

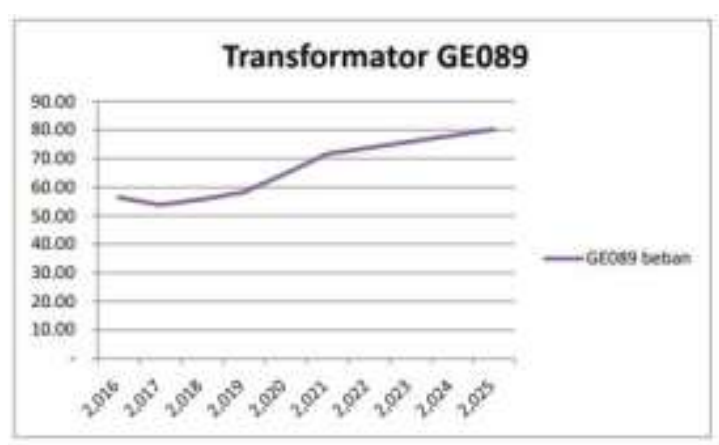

Gambar 5. Grafik pertumbuhan beban transformator GE089 untuk tahun 2016-2025 


\section{B.3 Persamaan Regresi Transformator GE089}

Menurut tabel "coefficients" output SPSS yang telah didapatkan hasil persamaan regresi pada output spss GE089 adalah sebagai berikut sebesar $Y=2311,493$ 0,099(x1) + 2,842e-010, dihasilkan peramalan beban untuk 5 tahun kedepan mulai tahun 2021 - tahun 2025 seperti pada Tabel 3

Berdasarkan peramalan beban puncak dan perhitungan presentase pembebanan pada Gambar 3 dan Gambar 5 dapat dilihat bahwa menunjukkan kenaikan yang signifikan untuk pertumbuhan beban puncak setiap tahunnya. Berdasarkan hasil prakiraan perhitungan menggunakan regresi linier untuk 5 tahun yang akan datang. Diketahui juga pada Tabel 1 dan Tabel 2, dapat diketahui nilai \% pembebanan pada transformator tersebut, dimana batas optimal pembebanan transformator sebesar 60\%-80\%. Semakin meningkatnya jumlah \% pembebanan maka penggunaan transformator semakin tidak optimal atau transformator mengalami kondisi overload/beban berat, dimana dalam kondisi tersebut transformator disarankan untuk diganti atau upgrade ke kapasitas yang lebih besar.

C. Pengembangan Trafo Distribusi 100 kVA dan 160 kVA Penyulang Jatimulyo

Menurut Hasil penelitian yang didapatkan untuk hasil peramalan beban transformator distribusi untuk kapasitas 100 kVA dan 160 kVA pada penyulang Jatimulyo untuk tahun 2021 sampai tahun 2022 didapatkan beberapa jumlah trafo yang mencapai beban berat atau sudah overload, untuk itu trafo tersebut perlu di upgrade kapasitasnya seiring dengan jumlah pertumbuhan beban transformator. Berikut daftar tabel transformator $100 \mathrm{kVA}$ dan $160 \mathrm{kVA}$ yang perlu diganti/diupgrade untuk setiap tahunnya:

Berdasarkan Pada Tabel 3 dijelaskan pada tahun 2021 terdapat pergantian trafo, dengan total pergantian sebanyak 13 trafo. Hal ini bertambah banyak karena pada tahun-tahun sebelumnya belum dilakukan pergantian transformator meskipun telah mencapai batas maksimum, hal itu bisa mengakibatkan kinerja transformator tidak optimal, sehingga pada tahun 2021 disarankan untuk menambah atau mengganti trafo apabila trafo telah mencapai batas maksimum.
Tabel 4. Daftar Transformator Distibusi 100 kVA dan $160 \mathrm{kVA}$ yang mengalami pergantian kapasitas

\begin{tabular}{|c|c|c|c|c|}
\hline \\
\hline $\mathrm{NO}$ & Tahun & Tipe & Lokasi & Keterangan \\
\hline 1 & \multirow{13}{*}{2021} & GE169 & Sabrang & $100 \rightarrow 160$ \\
\hline 2 & & GE166 & Wirowongso & $100 \rightarrow 160$ \\
\hline 3 & & GE227 & Sabrang & $100 \rightarrow 160$ \\
\hline 4 & & GE291 & Jatisari & $100 \rightarrow 160$ \\
\hline 5 & & GE273 & Sumberejo & $100 \rightarrow 160$ \\
\hline 6 & & GE220 & Krajan & $100 \rightarrow 160$ \\
\hline 7 & & GE330 & Klompangan & $100 \rightarrow 160$ \\
\hline 8 & & GE007 & Sabrang & $160 \rightarrow 200$ \\
\hline 9 & & GE061 & Pontang & $160 \rightarrow 250$ \\
\hline 10 & & GE168 & Andongsari & $160 \rightarrow 200$ \\
\hline 11 & & GE056 & Pontang & $160 \rightarrow 200$ \\
\hline 12 & & GE202 & Sabrang & $160 \rightarrow 250$ \\
\hline 13 & & GE081 & Gayasan & $160 \rightarrow 250$ \\
\hline 14 & \multirow{3}{*}{2022} & GE218 & Sumberejo & $100 \rightarrow 160$ \\
\hline 15 & & GE102 & Sumberejo & $160 \rightarrow 200$ \\
\hline 16 & & GE057 & Pontang & $160 \rightarrow 200$ \\
\hline 17 & 2023 & GE144 & Cangkring & $100 \rightarrow 160$ \\
\hline 18 & \multirow{3}{*}{2024} & GE025 & Sumberejo & $160 \rightarrow 200$ \\
\hline 19 & & GE093 & Sabrang & $160 \rightarrow 200$ \\
\hline 20 & & GE193 & Langon & $160 \rightarrow 200$ \\
\hline 21 & \multirow{2}{*}{2025} & GE089 & Sumberejo & $100 \rightarrow 160$ \\
\hline 22 & & GE202 & Sabrang & $250 \rightarrow 315$ \\
\hline
\end{tabular}

Pada tahun 2022 diperlukan penggantian atau penambahan kapasitas trafo sebanyak 3 buah, 1 trafo dari kapasitas 100 KVA menjadi $160 \mathrm{KVA}, 2$ buah trafo untuk 160 KVA menjadi 200 KVA. Tahun 2023 hanya terdapat satu pergantian kapasitas trafo dari $100 \mathrm{KVA}$ menjadi $160 \mathrm{KVA}$ untuk trafo dengan tipe GE144. Pada Tahun 2024 terdapat pergantian trafo dari GE56 kapasitas 160 KVA menjadi 200 KVA sebanyak 3 buah untuk trafo dengan tipe GE025, GE093, dan GE193.

Beban puncak mencapai batas maksimal (overload) pada transformator maka perencanaan penambahan beban transformator atau penggantian transformator harus segera dilakukan karena sifat suatu beban yang tumbuh akan semakin meningkat seiring dengan adanya pertumbuhan penduduk dan juga PDRB pada wilayah tersebut, sehingga perlu adanya langkah pengawasan yang intensif terhadap pertumbuhan beban trafo agar trafo tetap bekerja secara ideal. Karakteristik beban dapat berubah apabila faktor yang mempengaruhi beban yaitu jumlah penduduk dan PDRB menurun drastis sehingga penurunan beban terjadi dengan jumlah yang signifikan.

\section{KESIMPULAN}

Berdasarkan hasil perhitungan dan peramalan beban puncak Transformator 
distribusi 100 kVA dan 160 kVA, pada ULP Ambulu penyulang Jatimulyo didapatkan hasil pada tabel 5 dan 6 diatas dimana setiap peramalan beban pada transformator mulai tahun 2021 sampai tahun 2025 menunjukkan nilai beban puncak yang naik dan turun dari tahun sebelumnya. Hal ini disebabkan oleh pengaruh faktor jumlah penduduk dan PDRB, dimana pertumbuhan nilai PDRB sangat dominan daripada jumlah penduduk terhadap pertumbuhan beban puncak, dan dapat dilihat pada persamaan regresi transformator GE007 dan GE089 pada hasil persamaan tersebut apabila nilai variabel independent (PDRB) tetap dan nilai variabel (jumlah penduduk) mengalami kenaikkan 1\% maka artinya nilai $\mathrm{Y}$ akan mengalami penurunan sebesar koefisien $\left(b_{1}\right)$. Dan jika nilai variabel independent (Jumlah penduduk) tetap, dan koefisien (PDRB) mengalami kenaikan setiap $1 \%$, maka $Y$ akan mengalami peningkatan sebesar koefisien $\left(b_{2}\right)$. Dapat disimpulkan bahwa PDRB sangat mempengaruhi pertumbuhan beban puncak transformator. Pengaruh beban puncak dapat diakibatkan oleh adanya beban berlebih atau overload ketika pembebanan terjadi melebihi $80 \%$. Dan transformator pada kondisi tersebut disarankan untuk diganti agar kinerja transformator menjadi optimal.

\section{SARAN}

Saran untuk penelitian ini agar memperoleh pertimbangan yang lebih baik dan banyak tentang peramalan beban transformator jaringan distribusi, dimana dapat menggabungkan dua metode yang berbeda, sehingga dapat menjadi pembanding dan pertimbangan penggunaan metode yang cocok untuk peramalan beban. Serta dapat mempertimbangkan kepresisian jumlah penduduk dan PDRB yang tepat sesuai dengan wilayah transfromator yang akan digunakan.

\section{REFERENSI}

[1] Kumar Padmanabh. 2016. "Load Forecasting in India at Distribution Transformer considering Economic Dynamics". Proceedings of Intl. Conference on Advances in Computing, Communications and Informatics (ICACCI)

[2] Sanjay A. Deokar1, Laxman M. Waghmare2. 2011. "Analysis of Distribution Transformer Performance under Non-linear Balanced Load Conditions and Its Remedial
Measures", International Journal of Emerging Technology and Advanced Engineering (ISSN 2250-2459, Volume 1, Issue 2, December 2011.

[3] Bhatti Dhaval, Anuradha Deshpande. 2020. "Short-term Load Forecasting with Using Multiple Linier Regression". International Journal of Electrical and Computer Engineering (IJECE), Vol. 10, No. 4, August-2020, pp. 3911-3917

[4] S M. Dinesh Reddy. 2017. "Load Forecasting using Linier Regression Analysis in Time series model for RGUKT, R.K. Valley Campus HT Feeder". International Journal of Engineering Research and Technology (IJERT), Vol. 6, Issue 5, May-2017, pp. 624-625

[5] Harsh Patel, Mahesh Pandya, Mohan Aware. 2015. "Short Term Load Forecasting of Indian System Using Linear Regression and Artificial Neural Network," 5th Nirma University International Conference on Engineering (NUiCONE

[6] S.Saravanan,S.Kannan and C. Thangaraj. 2012 "India's Electricity Demand Forecast Using Regression Analysis and Artificial Neural Networks Based on Principal Components". ICTACT Journal On Soft Computing, vol. 2, no. 4. India

[7] Issac Adekunie. S, Adeyinka Ajao. A, Chihurumanya Felly. N, Ayokunle Awelewa. 2014. "Medium-Term Load Forecasting of Covenant University Using The Regression Analysis Methods," Journal of Energy Technologies and Policy, vol. 4, no. 4, pp. 10-16

[8] Xiong, T., Bao, Y., \& Hu, Z. 2014. "Interval forecasting of electricity demand: A novel bivariate EMD-based cıinport vector regression modeli framework". International Journal ot _......ical Power \& Energy Systems, 63, 353-362.

[9] Nedellec, R., Cugliari, J., \& Goude, Y. 2014. "Electric load forecasting and backcasting with semi-parametric models". International Journal of forecasting, 30(2), 375-381.

[10] Guilin Zheng, Li Zhang. 2015. "The Electrical Load Forecasting Base on an Optimal Selection Method of Multiple Models in DSM'. International Journal of Online Engineering, Vol 11 pages 8.

[11] Minaye, Emiyamrew dan Matewose, Melaku. 2013. "Long Term Load Forecasting of Jimma Town for Sustainable Energy Supply" . International Journal of Science and Research (IJSR), pp. 23192324.

[12] Gde Made Yoga Semadhi dan Ida Bagus Gede Manuaba. (2019). “Transformer's Load Forecasting to Find the Transformator Usage Capacitywith Adaptive Neuro-Fuzzy 
Inference System Method". Jurnal of Electrical and Engineering. Denpasar

[13] Syahputra, Ramadhoni dkk. (2018). "Application of Artifical Neural Network for Power Transformer Peak Load Prediction". Jurnal of Theoretical and Applied Information Technology.Vol.96 No.22. Yogyakarta 